JPE 11-4-23

\title{
Improved LVRT Capability and Power Smoothening of DFIG Wind Turbine Systems
}

\author{
Thanh Hai Nguyen* and Dong-Choon Lee ${ }^{\dagger}$ \\ $\dagger *$ Dept. of Electrical Engineering, Yeungnam University, Gyeongsan, Korea
}

\begin{abstract}
This paper proposes an application of energy storage devices (ESD) for low-voltage ride-through (LVRT) capability enhancement and power smoothening of doubly-fed induction generator (DFIG) wind turbine systems. A grid-side converter (GSC) is used to maintain the DC-link voltage. Meanwhile, a machine-side converter (MSC) is used to control the active and reactive powers independently. For grid disturbances, the generator output power can be reduced by increasing the generator speed, resulting in an increased inertial energy of the rotational body. Design and control techniques for the energy storage devices are introduced, which consist of current and power control loops. Also, the output power fluctuation of the generator due to wind speed variations can be smoothened by controlling the ESD. The validity of the proposed method has been verified by PSCAD/EMTDC simulation results for a 2 MW DFIG wind turbine system and by experimental results for a small-scale wind turbine simulator.
\end{abstract}

Key Words: DFIG, ESD, LVRT, Power smoothening, Wind power

\section{INTRODUCTION}

DFIG wind turbine systems equipped with converters rated at $25 \% \sim 30 \%$ of the system power capacity have become increasingly popular. Compared to fixed-speed cage-type induction generator wind turbines, variable-speed DFIG wind turbines provide the advantages of more power extraction and less mechanical stress. Also, when compared to permanent-magnet synchronous generator (PMSG) wind turbines equipped with full-scale converters, variable-speed DFIG wind turbines provide a lower system cost and lower power losses [1].

However, DFIG wind turbines are very sensitive to grid disturbances, especially to voltage dips, since they are connected directly to the grid. The ability of a wind turbine to survive a short voltage dip without tripping is referred to as the low-voltage ride-through (LVRT) capability. The LVRT requirement in the Danish grid code for wind turbine systems is shown in Fig. 1 [2]. On the other hand, the output power from wind turbines critically affects the frequency and voltage stabilities in power networks. This is especially true when its power capacity is very high. The power fluctuations from a turbine due to the wind speed variations incur deviations in the system frequency from the rated value. Therefore, it is necessary to suppress the power fluctuations of wind turbines.

For the LVRT capability of wind turbine systems, the crowbar has been applied, which is relatively a cheap solution with a simple control [3], [4]. However, the crowbar method

\footnotetext{
Manuscript received Dec. 28, 2010; revised May 2, 2011

Recommended for publication by Associate Editor Seung-Ho Song.

$\dagger$ Corresponding Author: dclee@yu.ac.kr

Tel: +82-53-810-2582, Fax: +82-53-810-4767, Yeungnam University

* Dept. of Electrical Eng., Yeungnam University, Korea
}

results in high transients for the generator currents, and the DFIG operates as a squirrel-cage induction generator and starts absorbing large amounts of reactive power from the power grid during grid faults. A static synchronous compensator (STAT$\mathrm{COM}$ ) was proposed to assist with the uninterrupted operation of a DFIG [5], [6]. The STATCOM is shunt-connected to the point of common coupling (PCC) of the system bus, in which the wind turbine is connected, to offer steady-state voltage regulation and to improve the short-term transient voltage stability. However, the STATCOM should be used together with the crowbar. Also, a static series compensator (SSC) or a dynamic voltage restorer (DVR) has been proposed to isolate a DFIG wind turbine from the voltage dips during the grid faults [7]. The DVR is a voltage-source converter (VSC) that is connected in series between the wind turbine generator and the grid, whose output voltage is added to compensate for grid voltage sags. The disadvantage of the DVR system is that it is relatively expensive.

A study of a DFIG wind turbine using an ESD for dealing with both LVRT and power smoothening has been introduced before [8], [9]. However its control algorithm and the design procedure for the ESD have not been investigated in detail and no experimental results have been provided. Application of an ESD for LVRT and power fluctuations has been also presented for use with PMSG wind turbine systems [10].

Control of the generator output power and the blade pitch angle exploiting the property of the high inertia of wind turbine systems can smoothen the power fluctuations and keep the frequency constant [11]-[14]]. A flywheel driven by an electrical machine has been presented in [15], [16] to smoothen power fluctuations. 


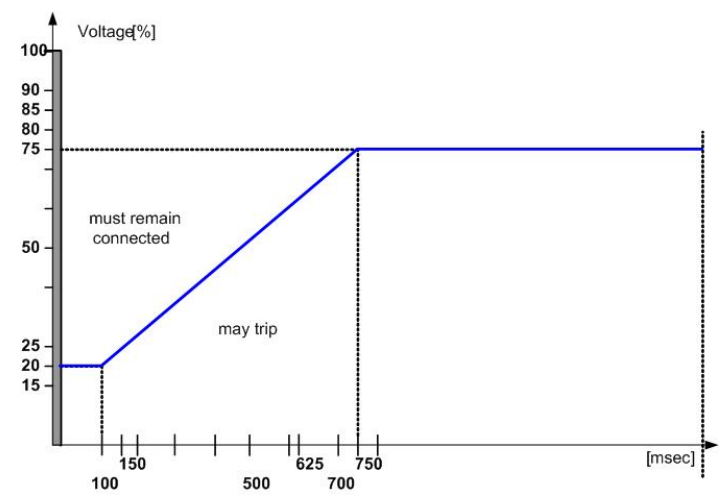

Fig. 1. Danish grid code [2].

In this paper, a ride-through technique for DFIG wind turbine systems using an ESD is proposed. The ESD consists of a DC-DC buck/boost converter and an electric double-layer capacitor (EDLC), which is connected at the DC-link side of back-to-back converters as shown in Fig. 2. The main concept of this method is to reduce the power produced from the turbine by increasing the inertial energy in the rotational body. By this, the energy capacity of the ride-through system can be decreased, which results in a low-cost system. In addition, the ESD integrated in the DFIG wind turbine system can also be used to improve the generator output power quality by storing or releasing the fluctuated power components due to wind speed variations. Simulations and experimental results are presented to verify the validity of the proposed method.

\section{Modeling OF DFIG Wind Turbine Systems}

\section{A. Modeling of a DFIG}

The DFIG equations for the fluxes, currents and voltages in a synchronously rotating $d-q$ reference frame are expressed as [17]:

$$
\begin{gathered}
\lambda_{d s}=L_{s} i_{d s}+L_{m} i_{d r} \\
\lambda_{q s}=L_{s} i_{q s}+L_{m} i_{q r} \\
\lambda_{d r}=L_{m} i_{d s}+L_{r} i_{d r} \\
\lambda_{q r}=L_{m} i_{q s}+L_{r} i_{q r} \\
v_{d s}=R_{s} i_{d s}+\frac{d \lambda_{d s}}{d t}-\omega_{e} \lambda_{q s} \\
v_{q s}=R_{s} i_{q s}+\frac{d \lambda_{q s}}{d t}+\omega_{e} \lambda_{d s} \\
v_{d r}=R_{r} i_{d r}+\frac{d \lambda_{d r}}{d t}-\left(\omega_{e}-\omega_{r}\right) \lambda_{q r} \\
v_{q r}=R_{r} i_{q r}+\frac{d \lambda_{q r}}{d t}+\left(\omega_{e}-\omega_{r}\right) \lambda_{d r} \\
T_{e}=-\frac{3}{2} \cdot \frac{L_{m}}{L_{s} \omega_{e}} \cdot v_{q s} i_{q r}
\end{gathered}
$$

where $R_{s}$ and $R_{r}$ are the stator and rotor resistance, $L_{l s}$ and $L_{l r}$ are the stator and rotor leakage inductance, $L_{m}$ is the magnetizing inductance. $L_{s}=L_{l s}+L_{m}, L_{r}=L_{l r}+L_{m}, v_{d q s}$ and $v_{d q r}$ are the $d-q$ stator and rotor voltages, $i_{d q s}$ and $i_{d q r}$ are the $d$ $q$ stator and rotor currents, $\omega_{e}$ and $\omega_{r}$ are the supply and rotor angular frequency, $\lambda_{d q s}$ and $\lambda_{d q r}$ are the $d-q$ stator and rotor flux linkages, respectively. $T_{e}$ is generator electromagnetic torque.

Under a stator flux-oriented vector control, the $q$-axis rotor current controls the generator torque or the stator active power of the DFIG, which is expressed as:

$$
P_{s}=\frac{3}{2}\left(v_{q s} i_{q s}+v_{d s} i_{d s}\right)=-\frac{3}{2} \cdot \frac{L_{m}}{L_{s}} \cdot v_{q s} i_{q r}
$$

On the other hand, the $d$-axis rotor current controls the stator reactive power, which is expressed as:

$$
Q_{s}=\frac{3}{2}\left(v_{q s} i_{d s}-v_{d s} i_{q s}\right)=\frac{3}{2} \cdot \frac{L_{m}}{L_{s}} \cdot v_{q s}\left(i_{m s}-i_{d r}\right)
$$

where $i_{m s}$ is the magnetizing current.

\section{B. Modeling of Wind Turbines}

The aerodynamic power of wind, $P_{\text {wind }}$, is expressed as:

$$
P_{\text {wind }}=\frac{1}{2} \rho A v^{3}
$$

where:

$A$ : blade swept area $\left[\mathrm{m}^{2}\right]$

$\rho:$ air density $\left[\mathrm{kg} / \mathrm{m}^{3}\right]$

$v$ : wind velocity $[\mathrm{m} / \mathrm{s}]$.

The mechanical power captured by the wind turbine is expressed as:

$$
P_{t}=0.5 \rho A C_{p}(\beta, \lambda) v^{3}
$$

where $C_{p}(\beta, \lambda)$ is the power conversion coefficient expressed as a function of the blade pitch angle $\beta$ and the tip-speed ratio $\lambda$. The tip-speed ratio is defined as:

$$
\lambda=\frac{\omega_{r} R}{v}
$$

where, $R$ is the radius of the blade [m].

The power conversion coefficient $C_{p}(\beta, \lambda)$ is a function of $\beta$ and $\lambda$ as follows:

$$
C_{p}(\beta, \lambda)=c_{1}\left(c_{2} \frac{1}{\Lambda}-c_{3} \beta-c_{4} \beta^{c_{5}}-c_{6}\right) \exp \left(-c_{7} \frac{1}{\Lambda}\right)
$$

in which:

$$
\frac{1}{\Lambda}=\frac{1}{\lambda+0.08 \beta}-\frac{0.035}{1+\beta^{3}}
$$

and $c_{1}-c_{7}$ are constants [18].

The maximum value, $C_{p \max }$, is obtained at a particular $\lambda_{\text {opt }}$ at a constant blade pitch angle. For maximum power extraction, $\lambda$ should be maintained at its optimal value $\lambda_{o p t}$, which is a design specification of the blade. The maximum output power of the turbines, $P_{t, \max }$, is expressed as:

$$
P_{t, \max }=0.5 \rho \pi R^{2} C_{p \max } v^{3}
$$




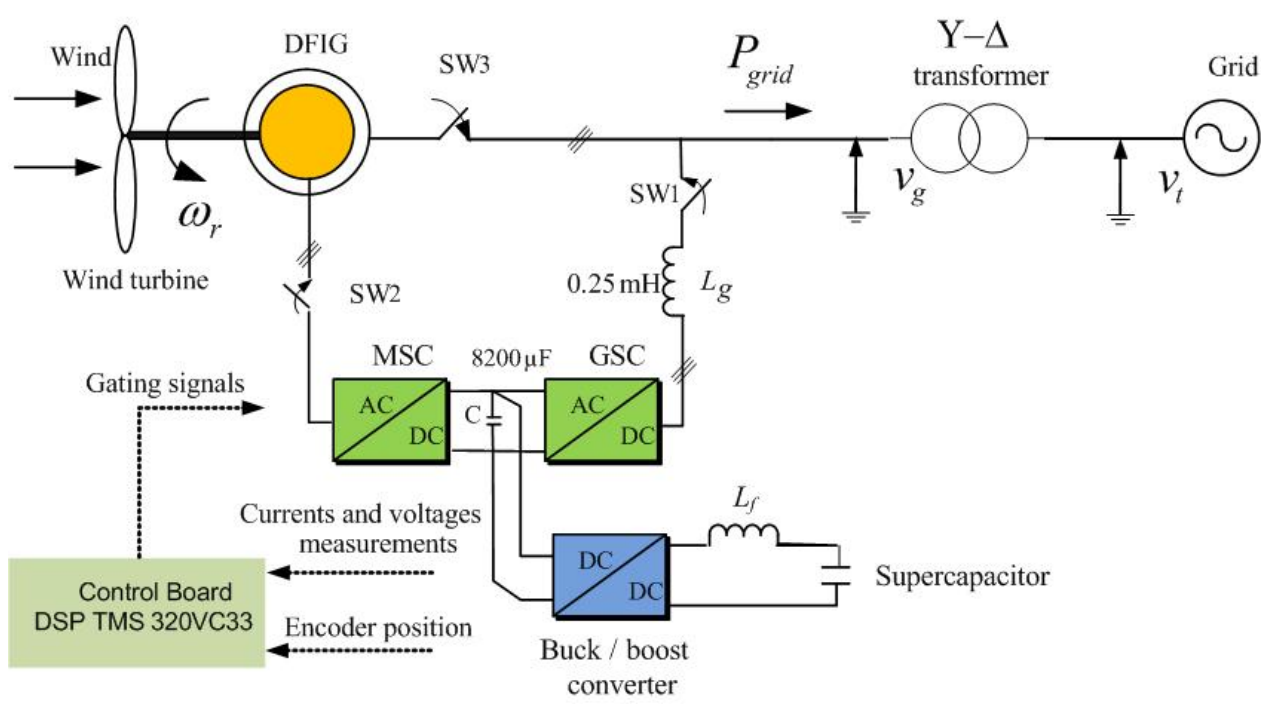

Fig. 2. DFIG wind turbine system with the ESD.

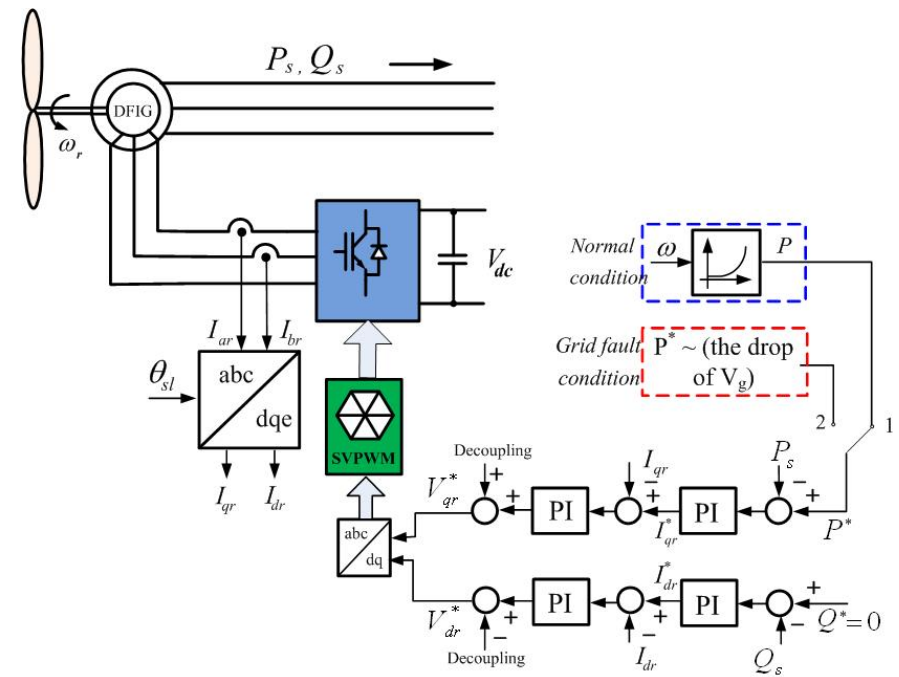

Fig. 3. Control block diagram of the DFIG.

\section{Control Scheme of DFIG Wind Turbine SYSTEMS}

\section{A. Energy Storage in Inertia}

The dynamic equations of the two-mass model of DFIG wind turbine systems are expressed as:

$$
\begin{aligned}
T_{t}-T_{k} & =J_{t} \frac{d \omega_{t}}{d t} \\
T_{k}-T_{g} & =J_{g} \frac{d \omega_{r}}{d t}
\end{aligned}
$$

where $T_{t}, T_{g}$ and $T_{k}$ are the turbine torque, the generator torque and the flexible coupling torque, respectively; $J_{t}$ and $J_{g}$ are the inertia of the turbine and generator, respectively; $\omega_{t}$ is the mechanical speed of the turbine.

Define the fault duration and the generator speed change as $\Delta T$ and $\Delta k(\%)$, respectively. From (18), (19), and the definition of the system inertia constant, the mechanical power, $P_{J}$, for speed variation is expressed as [19]:

$$
P_{J}=2 \cdot P_{\text {rated }}\left(H_{M}+H_{G}\right) \frac{\Delta k}{\Delta T}
$$

where, $H_{M}$ and $H_{G}$ are the inertia constants of the wind turbine and the generator, respectively, and $P_{\text {rated }}$ is the rated system power.

\section{B. Control of Back-to-Back Converters}

A grid-side converter (GSC) has a conventional cascaded control structure composed of an inner current control loop and an outer DC-link voltage control [20]-[22]. The GSC is controlled to maintain the DC-link voltage under both normal and grid disturbance conditions.

For the vector control of a DFIG, a cascaded control scheme composed of the inner current control loops for the d- and qaxes of the rotor currents and the outer power control loop for the stator active and reactive powers are employed. A control block diagram of the DFIG wind turbine is shown in Fig. 3. For a unity power factor at the generator stator terminal, the exciting current, $i_{m s}$, is supplied wholly from the rotor side. Therefore, the stator reactive power reference, $Q^{*}$, is set to zero. The MPPT method is applied for turbine power control, which gives the stator power reference, $P^{*}$, of the DFIG under normal grid conditions [23].

During grid voltage sags, however, the MPPT control stops and the power reference of the DFIG is set lower than it was before the sag. During this situation, the DFIG wind turbine operates as a flywheel and achieves the storage of the kinetic energy by an increase in system speed. However, this increase in system speed causes an increase in the tip-speed ratio which is not the optimum value. This results in a reduction of the turbine output power.

\section{Control Scheme of Energy Storage Devices}

\section{A. Control of the ESD}

The main role of the ESD is to store or release energy from the DFIG rotor-side or to the grid. For this purpose, a power controller is used in the main control loop with an inner current control loop for the ESD control as shown in Fig. 4. Under voltage sags, the GSC may not be able to fully deliver 


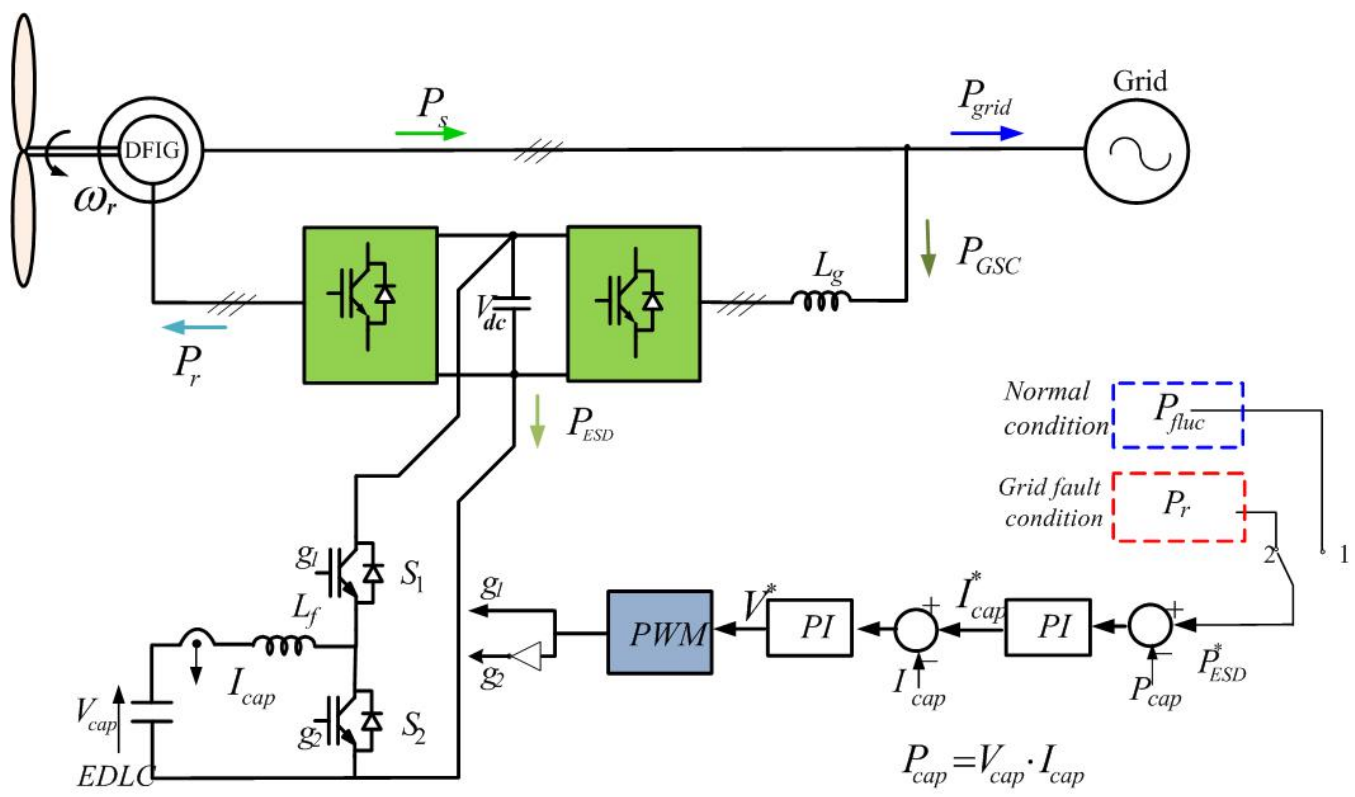

Fig. 4. Control block diagram of the ESD.

power from the rotor side to the grid due to a reduction of grid voltage. In order to keep the DC-link voltage constant, the ESD is activated to absorb the differential power between the MSC and the GSC. The power reference of the ESD, $P_{E S D}^{*}$, for LVRT is given by the rotor power, $P_{r}$, and is expressed as:

$$
P_{E S D}^{*}=P_{r} .
$$

Next, how to mitigate power fluctuations will be investigated below. Fluctuated power flows between the GSC and the grid. Therefore, for suppressing power fluctuations, the ESD should absorb or release the high-frequency components of the power, $P_{\text {fluc }}$, which are obtained through the second-order high-pass filter used for the generator power, $P_{g e n}$, as:

$$
P_{f l u c}=\frac{s^{2}}{s^{2}+2 \xi \omega_{c} s+\omega_{c}^{2}} P_{g e n}
$$

where $\xi$ is the damping ratio and $\omega_{c}$ is the cut-off frequency $\left(\omega_{c}=2 \pi f_{c}\right)$. In this paper, $\xi=0.707$ and $\omega_{c}=0.628 \mathrm{rad} / \mathrm{sec}[10]$. The generator power is expressed as:

$$
P_{\text {gen }}=P_{s}-P_{r}
$$

where $P_{S}$ is the stator power. The grid power can be smoothened by eliminating the high frequency components of the fluctuated power such as:

$$
\begin{aligned}
P_{\text {grid }} & =P_{s}-P_{G S C}=\left(P_{s}-P_{r}\right)-P_{E S D} \\
& =P_{\text {gen }}-P_{E S D}
\end{aligned}
$$

where $P_{G S C}$ and $P_{E S D}$ are the power of the GSC and the ESD, respectively.

\section{B. Rating of the ESD}

The power rating of the ESD, $P_{E S D_{-} \text {rated }}$, is chosen as that of back-to-back converters for full power absorbance, so that:

$$
P_{E S D_{-} \text {rated }}=(0.25 \sim 0.3) P_{\text {rated }} .
$$

The ESD energy capacity for power smoothening depends on the level of output power fluctuations. The frequency of the power fluctuations corresponds to that of the wind speed variations, which are expressed as:

$$
v_{w}(t)=V_{w 0}+\sum \Delta V_{w i} \sin \left(\omega_{i} t\right)
$$

where $V_{w 0}$ is the mean wind speed, $\Delta V_{w i}$ is the harmonic amplitude and $\omega_{i}$ is angular frequency $(f=0.1 \sim 10 \mathrm{~Hz})$. The charging or discharging cycles of the EDLC in the worst case scenario (for example, $f=0.1 \mathrm{~Hz}, T=10 \mathrm{~s}$ ) should be considered for safe and reliable operation. The ESD energy capacity has to be high enough so as to meet the highest wind speed condition. Therefore, the rated ESD energy is expressed as:

$$
E_{E S D_{-} \text {rated }}=\int_{0}^{T / 2} P_{E S D_{-} \text {rated }} \cdot \sin \left(\omega_{i} t\right) d t .
$$

During the ESD operation, the voltage of the EDLC varies. The capacitance of the EDLC, $C$, can be determined from the relation between the energy and the voltage as:

$$
C=\frac{2 \cdot E_{E S D_{-} \text {rated }}}{\Delta V_{\text {cap }} \cdot V_{\text {cap }}^{\text {rated }}}
$$

where $V_{\text {cap }}^{\text {rated }}$ and $\Delta V_{\text {cap }}$ are the rated voltage and the voltage variation of the EDLC, respectively.

Next, the LVRT capability of a DFIG wind turbine system using the ESD is considered. Since the duration of a grid fault is much shorter than the duration of power smoothening, the energy flow into the ESD is much lower than it is for power smoothening. Therefore, the ESD capacity designed above can satisfy the LVRT requirement.

\section{Simulation Results}

For testing the LVRT capability of wind turbine systems, PSCAD/EMTDC simulations have been performed for a $2[\mathrm{MW}]$ DFIG wind turbine system. The parameters for 


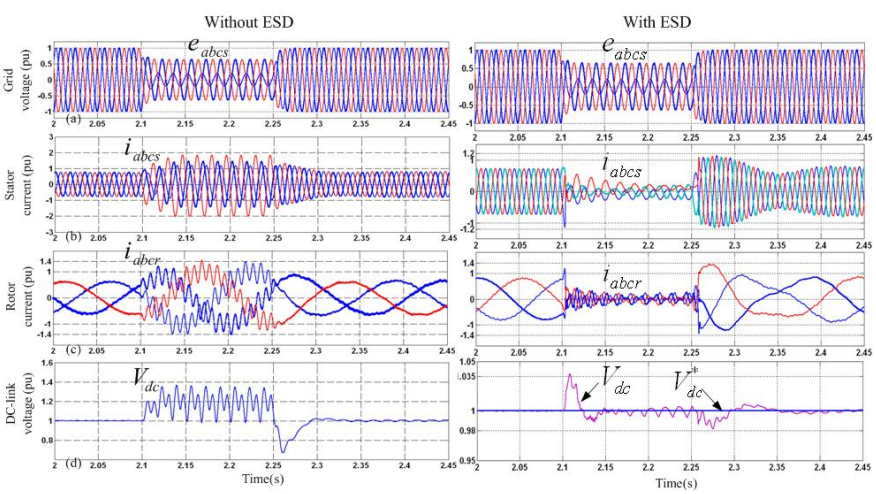

Fig. 5. Responses of DFIG wind turbine system without and with ESD. (a) Grid voltage, (b) stator currents, (c) rotor currents, (d) DC-link voltage.
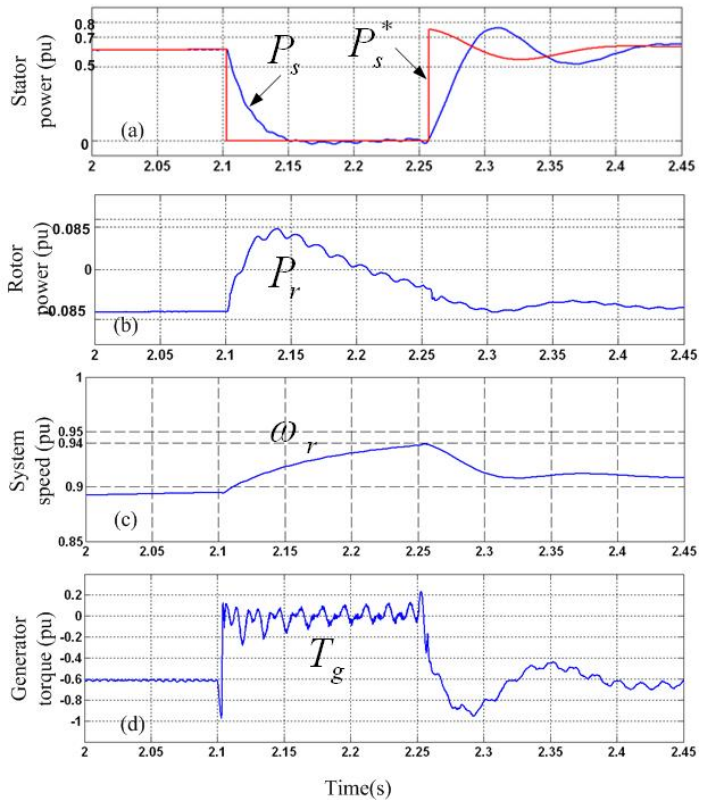

Fig. 6. Performance of DFIG. (a) Stator power, (b) rotor power, (c) rotor speed, (d) generator torque.

the wind turbine and the DFIG are listed in Table I and II, respectively. The grid voltage is $0.69[\mathrm{kV}] / 60[\mathrm{~Hz}]$. The switching frequency for both converters is $2.5[\mathrm{kHz}]$.

Fig. 5 shows the responses of the DFIG wind turbine system both with and without the use of the ESD under an unbalanced grid voltage as shown in Fig. 5(a), with a constant wind speed of $12.5[\mathrm{~m} / \mathrm{s}]$. The stator and rotor

currents of the DFIG are shown in Fig. 5(b) and (c), respectively. They are limited to within the allowable range by a reduction of the generator power reference and the power absorbance of the ESD. The DC-link voltage of the back-toback converters is also kept closely to the rated value as shown in Fig. 5(d). However, as can be seen in Fig. 5, these quantities oscillate severely in the case of not using the ESD.

Fig. 6(a) shows the control performance of the stator power, which is decreased during grid faults. The rotor power is shown in Fig. 6(b). Due to the reduction of the power reference, the power difference between the turbine and the DFIG accelerates the system. Fig. 6(c) shows the rotor speed increase during grid faults. The generator torque is shown in Fig. 6(d), which is also reduced and fluctuated due to the

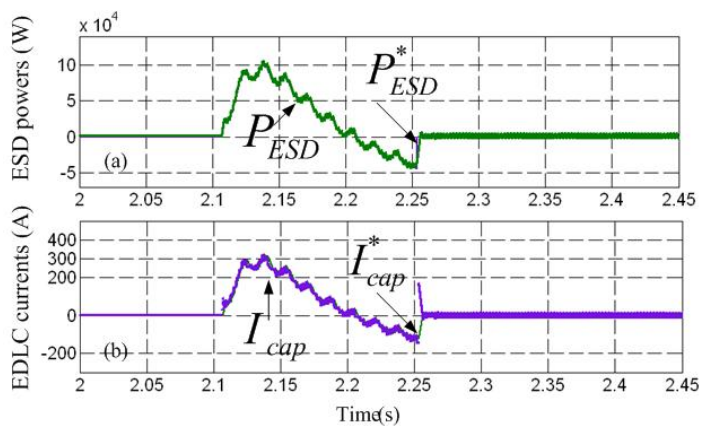

Fig. 7. Performance of the ESD. (a) ESD power, (b) EDLC current.
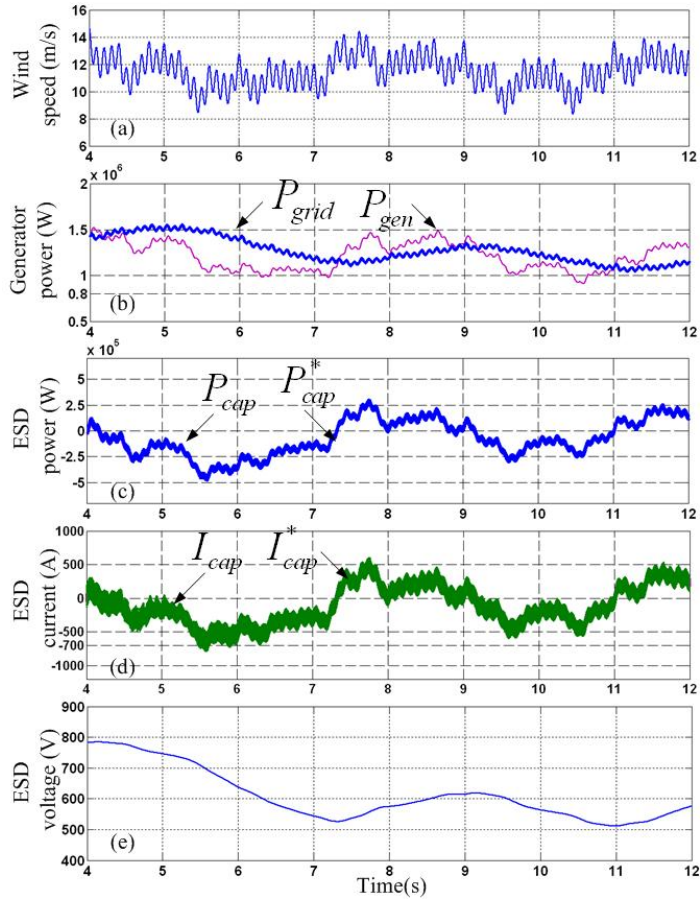

Fig. 8. Responses of system for wind speed variation. (a) Wind speed, (b) generator power, (c) rotor and GSC power, (d) ESD power, (e) ESD current, (f) ESD voltage.

unbalanced grid sags.

Fig. 7 shows the performance of the ESD in which the power and current controllers are shown in Fig. 7(a) and (b), respectively. The control performance is good.

Fig. 8 shows the response of the system when the wind speed varies as shown in Fig. 8(a). The fluctuated components of the generator power are alleviated before flowing into the grid. Thus, the grid power becomes smoother than the generator power as shown in Fig. 8(b). Fig. 8(c) shows the rotor and GSC powers. They are different since the GSC delivers not only the rotor power but also the high frequency components of the generator power. The performance of the ESD is shown in Fig. 8(d)-(f). Fig. 8(d) shows the performance of the power controller and the fluctuated component of the generator power. The performance of the current controller is good as shown in Fig. 8(e). During the operation of the ESD, the EDLC voltage varies as shown in Fig. 8(f).

\section{EXPERIMENTAL RESULTS}

Experimental tests were performed on a $3[\mathrm{~kW}]$ DFIG wind turbine simulator to verify the validity of the proposed method. 


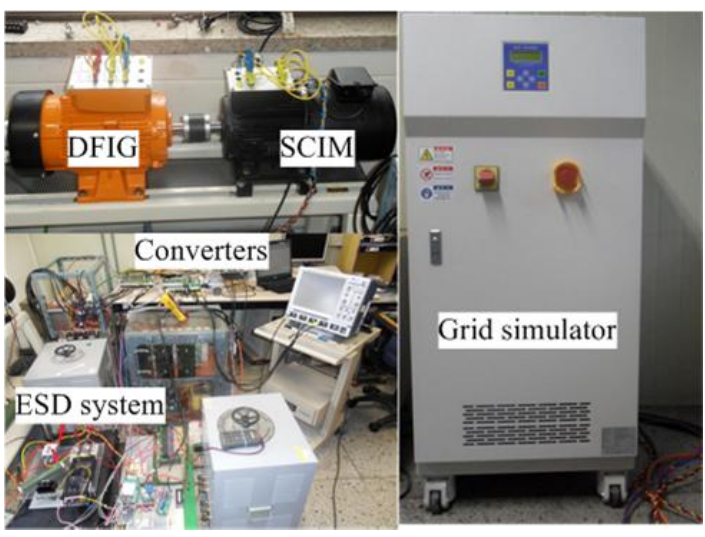

Fig. 9. Experimental setup for DFIG-ESD system.

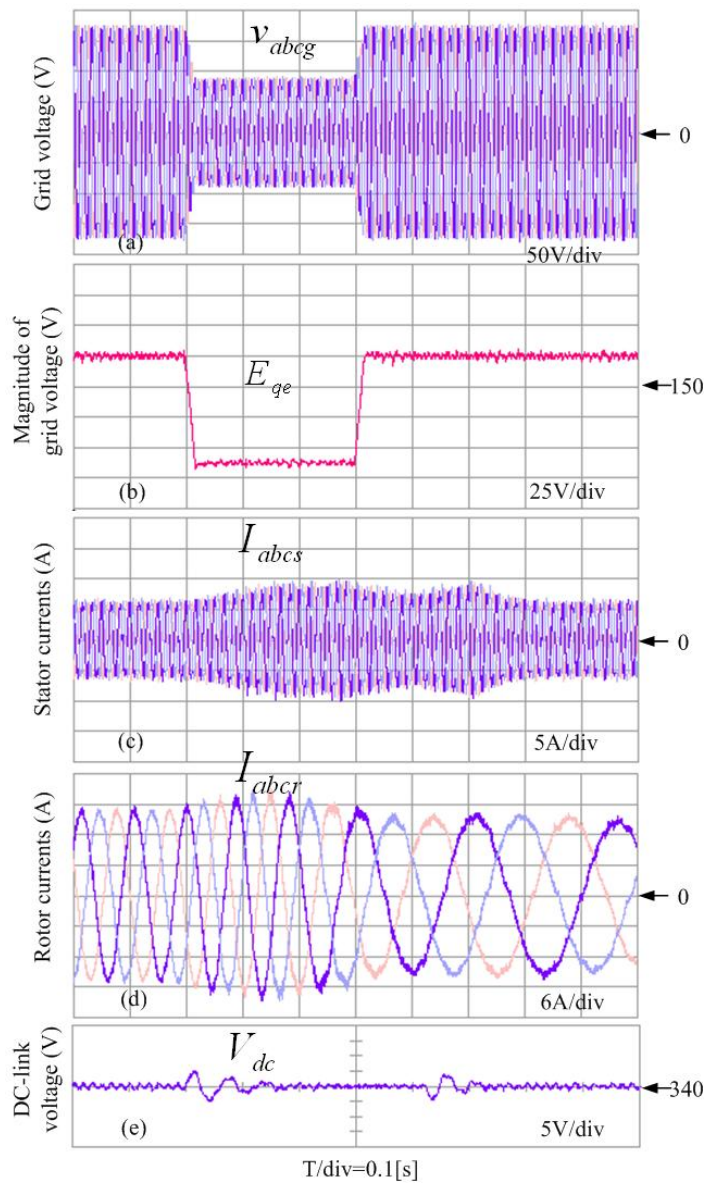

Fig. 10. Control performance of back-to-back converters. (a) Instantaneous grid voltage, (b) magnitude of grid voltage, (c) stator currents, (d) rotor currents, (e) DC-link voltage.

The DFIG is coupled with a $3[\mathrm{~kW}]$ squirrel-cage induction motor (SCIM) controlled by back-to-back converters providing torque regulation according to the characteristics of the wind turbines. For a sag generator, a 10kVA grid simulator is used. The experimental setup is shown in Fig. 9. The parameters of the DFIG and the energy storage device are shown in Table III, and Table IV, respectively. The grid voltage is $220[\mathrm{~V}] / 60[\mathrm{~Hz}]$. The DC-link voltage is controlled at 340[V] for the IGBT back-to-back PWM converters, which have a switching frequency of $5[\mathrm{kHz}]$.

For a grid fault, the amplitude of the three phase voltages

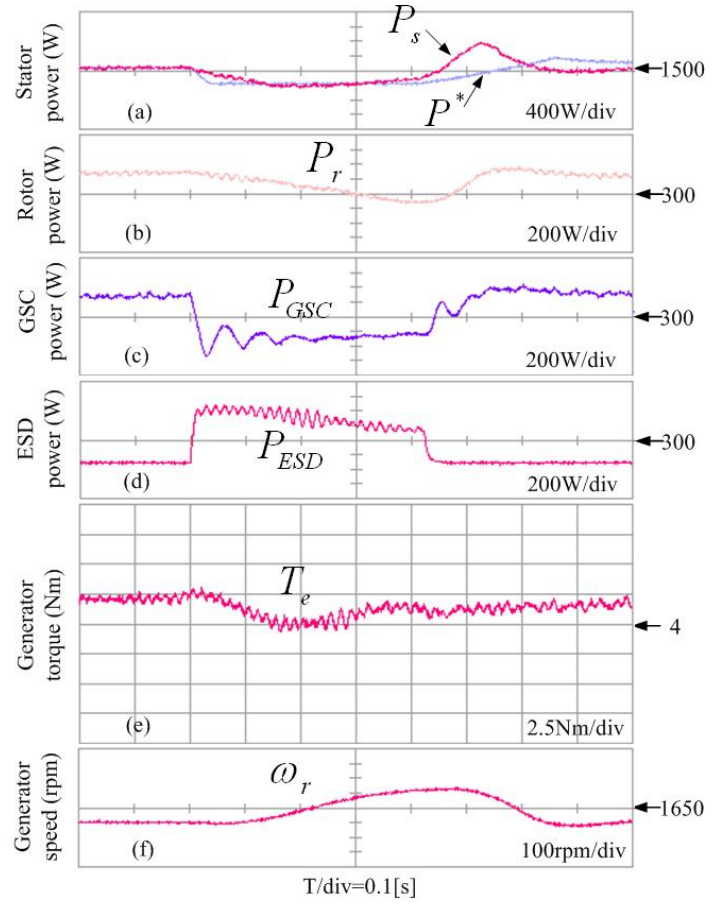

Fig. 11. System performance. (a) Stator power, (b) rotor power, (c) GSC power, (d) ESD power, (e) generator torque, (f) generator speed.

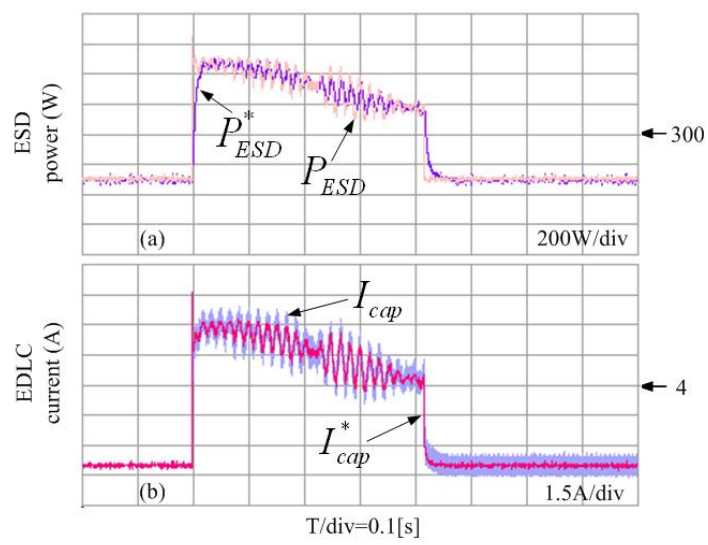

Fig. 12. Control performance of ESD. (a) Power, (b) current.

of the grid are reduced at the same time, as shown in Fig. 10(a) and (b), for the three-phase instantaneous grid voltage and the magnitude of grid voltage, respectively, where $50 \%$ of the sags are generated. Fig. 10(c) and (d) show the stator and rotor currents. During grid fault, these currents are increased due to a reduction of the stator voltage. The DC-link voltage of the back-to-back converters is kept at its reference value.

Fig. 11 shows the power balance associated with the turbine simulator, the generator, the grid, the ESD and the acceleration of the system. When the gird fault occurs, the stator power is reduced as shown in Fig. 11(a). The rotor power is shown in Fig. 11(b). During the fault, the GSC power is decreased due to the operation of the ESD as shown in Fig. 11(c) and (d). The generator torque in Fig. 11(e) is also reduced since the reduction of the generator power results in an increase of the generator speed as shown in Fig. 11(f). Fig. 12(a) and (b) show the performance of the ESD for power and current controllers, respectively. 


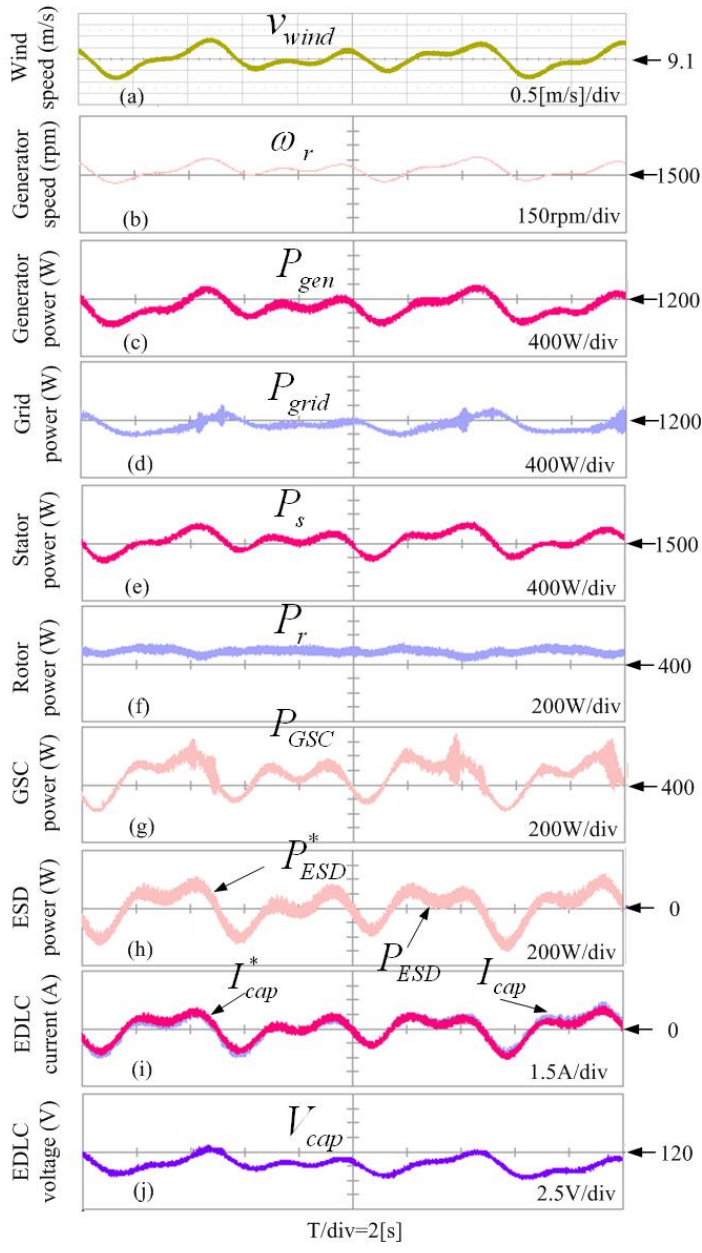

Fig. 13. Responses of system for wind speed variation. (a) Wind speed, (b) generator speed, (c) generator power, (d) grid power, (e) stator power, (f) rotor power, (g) GSC power, (h) ESD power, (i) EDLC current, (j) EDLC voltage.

Next, the validity of the proposed control scheme is investigated in the case of power fluctuations due to wind speed variations. The waveforms for this case are shown in Fig. 13. The wind speed is shown in Fig. 13(a). The generator speed is also fluctuated as shown in Fig. 13(b). The generator power is fluctuated as shown in Fig. 13(c). Due to the ESD, the grid power can be smoothened as shown in Fig. 13(d). Fig. 13(e) and (f) show the stator and rotor powers, respectively. The GSC power in Fig. 13(g) is different from the rotor power due to the operation of the ESD. Fig. 13(h) and (i) show the performance of the power and current controllers of the ESD, respectively. Fig. 13(j) shows the capacitor voltage, which is varied according to the charging and discharging.

\section{CONCLUSIONS}

This research has investigated an enhanced LVRT capability for DFIG wind turbine systems using energy storage devices. A coordinated control strategy for the MSC, the GSC, and the ESD has been proposed. The proposed system can absorb the fluctuations of the generator output power, so that the power delivered to the grid is smoothened. Therefore, the power system can operate more stably. The simulation results for a 2[MW] DFIG wind turbine system and the experimental results for a small-scale turbine simulator have shown the feasibility of the proposed method.

\section{APPENDIX}

The parameters of the generator, the wind turbine and the ESD used for the simulation and the experiment are listed in Table I - IV.

TABLE I

PARAMETERS OF WIND TURBINE

\begin{tabular}{|l|l|}
\hline Rated power & $2[\mathrm{MW}]$ \\
\hline Blade radius & $44.18[\mathrm{~m}]$ \\
\hline Air density & $1.225\left[\mathrm{~kg} / \mathrm{m}^{3}\right]$ \\
\hline Max. power conv. coefficient & 0.40 \\
\hline Optimal tip-speed ratio & 8.0 \\
\hline Cut-in/cut-of speed & $3[\mathrm{~m} / \mathrm{s}] / 25[\mathrm{~ms}]$ \\
\hline Rated wind speed & $11[\mathrm{~m} / \mathrm{s}]$ \\
\hline Blade inertia & $6.3 \times 106\left[\mathrm{~kg} . \mathrm{m}^{2}\right]$ \\
\hline
\end{tabular}

TABLE II

PARAMETERS OF DFIG FOR SIMULATION

\begin{tabular}{|l|l|}
\hline Rated power & $2[\mathrm{MW}]$ \\
\hline Stator voltage/frequency & $690[\mathrm{~V}] / 60[\mathrm{~Hz}]$ \\
\hline Stator resistance & $0.00488 \mathrm{pu}$ \\
\hline Rotor resistance & $0.00549 \mathrm{pu}$ \\
\hline Stator leakage inductance & $0.0924 \mathrm{pu}$ \\
\hline Rotor leakage inductance & $0.0995 \mathrm{pu}$ \\
\hline Generator inertia & $200\left[\mathrm{~kg} \cdot \mathrm{m}^{2}\right]$ \\
\hline
\end{tabular}

TABLE III

PARAMETERS OF DFIG FOR EXPERIMENT

\begin{tabular}{|l|l|}
\hline Rated power & $3[\mathrm{~kW}]$ \\
\hline Stator voltage/frequency & $220[\mathrm{~V}] / 60[\mathrm{~Hz}]$ \\
\hline Stator resistance & $0.0372 \mathrm{pu}$ \\
\hline Rotor resistance & $0.04419 \mathrm{pu}$ \\
\hline Stator leakage inductance & $0.07737 \mathrm{pu}$ \\
\hline Rotor leakage inductance & $1.5592 \mathrm{pu}$ \\
\hline Generator inertia & $0.0033\left[\mathrm{~kg} . \mathrm{m}^{2}\right]$ \\
\hline
\end{tabular}

TABLE IV

PARAMETERS OF ESD FOR EXPERIMENT

\begin{tabular}{|l|l|}
\hline Inductor $\left(L_{f}\right)$ & $2.5[\mathrm{mH}]$ \\
\hline Supercapacitor & $2.92[\mathrm{~F}]$ \\
\hline DC operating voltage & $120[\mathrm{~V}]$ \\
\hline Switching frequency & $5[\mathrm{kHz}]$ \\
\hline
\end{tabular}

\section{ACKNOWLEDGEMENT}

This research has been supported by the Basic Science Research Program through the National Research Foundation of Korea (NRF) funded by the Ministry of Education, Science and Technology (2009-0077374).

\section{REFERENCES}

[1] J. Lopez, E. Gubia, P. Sanchis, X. Roboam, and L. Marroyo, "Wind turbines based on doubly fed induction generator under asymmetrical voltage dips," IEEE Trans. Energy Convers., Vol. 23, No. 1, pp. 321330, Mar. 2008.

[2] T. Ackermann, J. R. Abbad, I. M. Dudurych, I. Erlich, H. Holttinen, J. R. Kristoffersen, and P. E. Sorensen, "European balancing act," IEEE Power and Energy Magazine, Vol. 5, No. 6, pp. 90-103, Nov./Dec. 2007. 
[3] V. Akhmatov, "Analysis of dynamic behavior of electric power systems with large amount of wind power," Ph.D. dissertation, Tech. Univ. Denmark, Kgs. Lyngby, Denmark, Apr. 2003.

[4] J. Morren and S. W. H. de Haan, "Ride-through of wind turbines with doubly-fed induction generator during a voltage dip," IEEE Trans. Energy Convers., Vol. 20, No. 2, pp. 435-441, Jun. 2005.

[5] B. Singh, R. Saha, A. Chandra, and K. Al-Haddad, "Static synchronous compensators (STATCOM): a review," IET Power Electron., Vol. 2, No. 4, pp. 297-324, 2009.

[6] W. Qiao, G. K. Venayagamoorthy, and R. G. Harley, "Real-time implementation of a STATCOM on a wind farm equipped with doubly-fed induction generator," IEEE Trans. Ind. App., Vol. 45, No. 1, pp. 98-107, Jan./Feb. 2009.

[7] A. O. Ibrahim, T. H. Nguyen, D. C. Lee, and S. C. Kim G, "Ridethrough strategy for DFIG wind turbine systems using dynamic voltage restorers," in Proc. IEEE- ECCE, Sep. 2009.

[8] C. Abbey and G. Joos, "Supercapacitor energy storage for wind energy applicatons," IEEE Trans. Ind. App., Vol. 43, No. 3, pp. 769-776, May/Jun. 2007.

[9] T. H. Nguyen and D. C. Lee, "LVRT and power smoothening of DFIG wind turbine system using energy storage device," in Proc. ICCAS, Oct. 2010.

[10] T. H. Nguyen and D. C. Lee, "Ride-through technique for PMSG wind turbine using energy storage systems", Journal of Power Electronics, Vol. 10, No. 6, pp. 733-738, Nov. 2010.

[11] P. K. Keung, P. Li, H. Banakar, and B. T. Ooi, "Kinetic energy of windturbine generators for system frequency support," IEEE Trans. Power Syst., Vol. 24, No. 1, pp. 279-287, Feb. 2009.

[12] C. Luo, H. Banakar, B. Shen, and B. T. Ooi, "Strategy to smooth wind power fluctuation of wind turbine generator," IEEE Trans. Energy Convers., Vol. 22, No. 2, pp. 341-349, Jun. 2007.

[13] H. Geng and G. Yang, "Output power control for variable-speed variablepitch wind generation systems," IEEE Trans. Energy Convers., Vol. 25, No. 2, pp. 494-503, Jun. 2010.

[14] E. Muljadi and C. P. Butterfield, "Pitch-controlled variable-speed wind turbine generation", IEEE Trans. Ind. App., Vol. 37, No. 1, pp. 240-246, Jan./Feb. 2001.

[15] J. M. Carrasco, L. G. Franquelo, J. T. Bialasiewicz, E. Galvan, R. C. P. Guisado, M. A. M. prats, J. I. Leon, and M. Alfonso, "Power-electronic system for the grid integration of renewable energy sources: a survey," IEEE Trans. Ind. Electro., Vol. 53, No. 4, pp. 1002-1016, Aug. 2006.

[16] R. Cardenas, G. Asher, R. Pena, and J. Clare, "Power smoothing control using sensorless flywheel drive in wind -diesel generation system," in Proc. 28th Аnnu. IEEE IECON, Seville, Spain, pp. 3303-3308, 2002.
[17] R. Pena, "Doubly-fed induction generator using back-to-back PWM converter and its application to variable-speed wind-energy generation," IEE Proc. B, Vol. 143, No. 3, pp. 231-241, 1996.

[18] Z. Lubosny, Wind turbine operation in electric power system, SpringerVerlag Berlin Heidelberg New York, Chap. 5, 2003.

[19] V. Akhmatov, Induction generators for wind power, Multi-Science Publishing Company, Chap. 3, 2005.

[20] J.-I. Jang and D.-C. Lee, "High performance control of three-phase PWM converters under nonideal source voltage," in Proc. of IEEE- ICIT, pp. 2791-2796, Dec. 2006.

[21] H- S. Song and K. Nam, "Dual current control scheme for PWM converter under unblanced input voltage conditions", IEEE Trans. Ind. App., Vol. 46, No. 5, pp. 953-959, Oct. 1999.

[22] S. B. Lee, K. B. Lee, D. C. Lee, and J. M. Kim, "An improved control method for a DFIG in a wind turbine under an unbalanced grid voltage condition," Journal of Electrical Engineering \& Technology, Vol. 5, No. 4, pp. 614-622, Nov. 2010.

[23] S. M. Barakati, M. Kazerani, and D. Aplevich, "Maximum power tracking control for a wind turbine system including a matrix converter", IEEE Trans. Energy Convers., Vol. 24, No. 3, pp. 705-713, Sep. 2009.

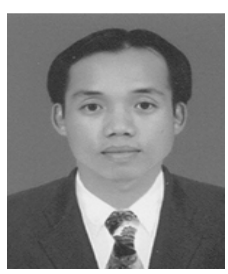

Thanh Hai Nguyen was born in Dong Thap, Viet Nam in 1980. He received his B.S. in Engineering from the Technology University of Ho Chi Minh City, Viet Nam, in 2003, and his M.S. in the Department of Electrical Engineering, Yeungnam University, Gyeongsan, Korea, in 2010, where he is currently working toward his $\mathrm{Ph} . \mathrm{D}$. He was an Assistant Lecturer in the College of Technology, Can Tho University, Viet Nam, in 2003. His current research interests include power converters, machine drives, and wind power generation.

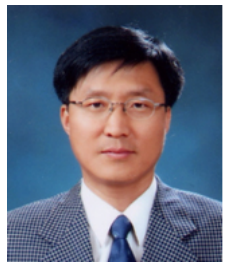

Dong-Choon Lee received his B.S., M.S., and Ph.D. in Electrical Engineering from Seoul National University, Seoul, Korea, in 1985, 1987, and 1993, respectively. He was a Research Engineer with Daewoo Heavy Industry from 1987 to 1988. Since 1994, he has been a Faculty Member in the Deptartment of Electrical Engineering, Yeungnam University, Gyeongsan, Korea. As a Visiting Scholar, he joined the Power Quality Laboratory, Texas A\&M University, CityCollege Station, USA, in 1998, the Electrical Drive Center, CityUniversity of Nottingham, U.K., in 2001, and the Wisconsin Electric Machines and Power Electronic Consortium, University of Wisconsin, Madison, USA, in 2004. Presently, he is a Publication Editor of the JPE. His current research interests include ac machine drives, the control of power converters, wind power generation, and power quality. 